\title{
Issues Facing Design Professionals through the Lens of Two Rain-Induced Roof Collapses
}

\author{
J. W. Lawson ${ }^{1}$ and M. E. Parolini ${ }^{2}$ \\ ${ }^{1}$ Associate Professor and Structural Engineer, Architectural Engineering Department, Cal Poly \\ State Univ., San Luis Obispo, CA 93407. E-mail: jwlawson@calpoly.edu \\ ${ }^{2}$ Principal Structural Engineer, Smith Structural Group, San Luis Obispo, CA 93401. E-mail: \\ michael@smithstructural.com
}

\begin{abstract}
The drainage of low-sloped roof systems involves multiple design professionals, and often each has a different opinion as to their design responsibility. Roofing issues have been identified as being a number one source of litigation, and rain-induced roof collapses continue to occur with alarming frequency. With the backdrop of several rain-induced roof collapses, this paper illustrates the complexity of assigning design responsibility for drainage systems; and investigates a variety of outcomes associated with the current building code provisions transporting rainwater from large low-sloped roof structures.
\end{abstract}

\section{INTRODUCTION}

The use of low-sloped roofs with parapets are popular in large buildings where space and volume maximization are important such as big-box retail and warehouses. The International Building Code (IBC) (ICC 2012a) requires a primary drainage system, and a back-up secondary (emergency) drainage system to prevent excessive rainwater loads on the roof should the primary drain become blocked or overwhelmed with excessive rainfall.

For the seemingly simple process of transporting water off a roof, the interdisciplinary roles of the parties involved are more complex than may first appear. It is common practice for the stakeholders to not be in direct communication with one another, and to make assumptions as to each other's design responsibility and/or design intent, resulting in avoidable errors.

Most devastating are the frequent rain-induced roof collapses reported each year, putting people's lives at risk in addition to the millions of dollars in property damage. Both low-sloped wood roof systems and steel roof systems (Figure 1) are susceptible. Frequently these failures are not initiated by a structural deficiency but instead are related to poor design of, poor execution of, or poor maintenance of the roof drainage system. The authors have observed undersized primary and secondary drainage system, missing or blocked overflow systems, and portions of roofs that are nearly dead flat causing ponding water. The problems are widespread enough that others have called for tighter regulations and an education campaign to be put in place (Jordan 2005; Patterson and Mehta 2010; Verhulst et al. 2010). 


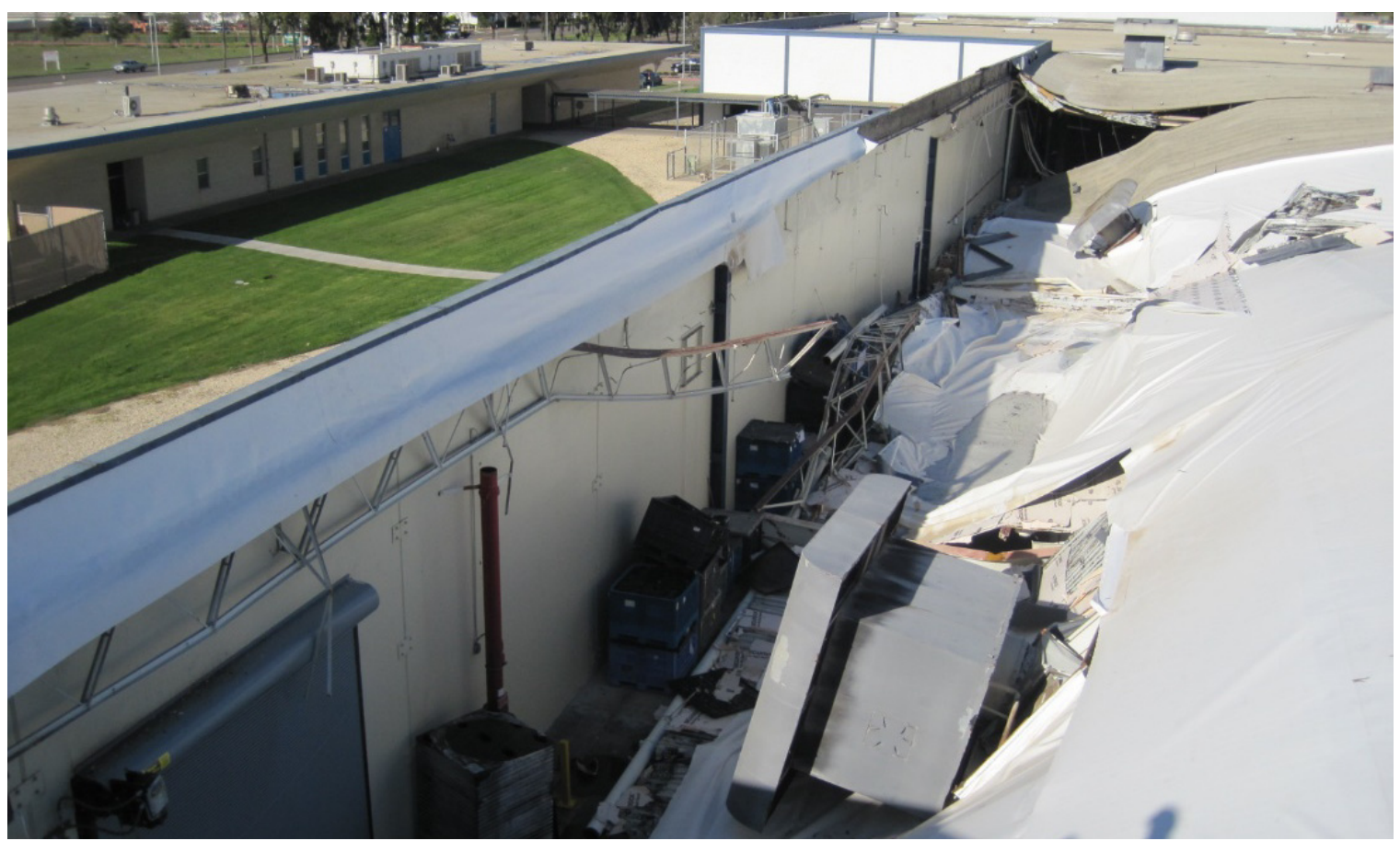

Figure 1 - Excessive rainwater load causes a steel roof structure to collapse. (Source: John Lawson)

\section{SEARCHING FOR RESPONSIBILITY}

With a mixture of overlapping design disciplines involving the architect, plumbing consultant and structural engineer, the assignment of roles for developing proper roof drainage is commonly not fully addressed during building design and can lead to the ponding of rain water, the roof drains/scuppers being undersized, and/or inadequate structural support for the rain loads. It is in the best interest of all parties involved to be proactive and establish a code complying roof drainage design in order to minimize litigation exposure should a problem develop.

For example in the winter of 1998 in Irvine, California, a rainstorm caused 18-inches of water to collect on the roof due to leaves clogging the drains' dome strainers, leading to a partial roof collapse of a major computer manufacturer's warehouse facility, flooding the building, and resulting in millions of dollars of damages to both the building and the contents therein. In this case, the building was constructed of tilt-up concrete walls with a low-sloped panelized wood structural roof system. The building owner's insurance company who paid on the claim aggressively pursued, through costly litigation, those presumed responsible in order to recoup their substantial costs. In a state with joint and several liability, many parties often must defend themselves regardless of the portion of perceived responsibility. Should the architect have provided an open parapet scupper penetration instead of the interior secondary drain which clogged with leaves? Should the plumber not specify dome strainers which are susceptible to clogging? Did the landscape architect contribute to the damages by specifying large deciduous trees on the side of the building which happens to typically be upwind? Did the owner or tenant not provide regular roof cleanings? Did the City cause the drainage problem by not permitting unsightly overflow drainage scuppers, and thus forcing the architect to use an interior overflow drain susceptible to clogging? Also, did the City's recommendation to visually screen the building with large deciduous trees contribute? Did the contractor install a defective wood beam 
that eventually failed? Did the structural engineer design a proper roof structure without an error or omission?

While not all these theories will prevail in the end, it is still in the best interest of the design team members to look out for each other, thus reducing the risk to themselves from being brought into a future lawsuit. Most importantly, understanding and clearly defining to others your role in the design of the roof drainage system will go a long way to separating your design firm from being unfairly dragged into a protracted legal battle after a damage claim. However, as will be discussed the roles of the various design parties contain significant overlap, thus closer coordination is recommended.

\section{DETERMINING DESIGN RESPONSIBILITY}

To discuss the responsibility of roof drainage design, it is helpful to review the overall concepts at work. As rainwater falls on a roof, it should continuously flow down slope across the roofing surface, hopefully without ponding. Traditionally, architects establish the building shape and size, including roof geometry and drainage slope and direction. Roofing materials and cricket requirements are also typically selected by the architect or their roofing consultant. In many cases, the architect also works with a plumbing (or mechanical) consultant to determine the roof drainage style, number of roof drains, and the roof drain locations.

Armed with this knowledge, the plumbing consultant computes the required water flow and sizes the primary and secondary roof drainage and all associated piping as necessary to stay within the framework of the architectural design. Primary drains are designed to transport all the water in a design storm event, and secondary drains provide a redundant emergency backup system should the primary system fail for any reason. For this emergency system, the plumbing consultant is either designing a second redundant drain pipe system or a scupper hole through the parapet wall to relieve the roof from any overloads. The type of system necessary is usually at the direction of the architect, or at times mandated by the city or county jurisdiction as was illustrated in the previous case study presented.

It is important to mention that as the water reaches the predetermined drainage collection points, water will naturally accumulate and rise to some height over the drain pipe or scupper inlet; and this height is the necessary hydraulic head to create flow pressure. The more water head, the more water flow, but unfortunately also the more water weight on the roof, and this water weight can exceed the design roof live load over portions of the roof (See Figure 2). Whose responsibility is it for notifying, addressing or limiting this water weight on the roof? The architect selecting the roof configuration? The plumbing consultant selecting the drain size? The structural engineer designing the roof structure?

With multiple parties potentially involved in the success of the roof drainage system, it is necessary for the parties to agree on their respective areas of responsibility but more importantly communicate their intentions and resulting ramifications to the others involved. ASCE 7-10 Minimum Design Load for Buildings and Other Structures (ASCE 2010) recognizes the importance of communication among the design professionals by stating in Commentary Section C8.2, "Roof drainage is a structural, architectural, and mechanical (plumbing) issue... Design team coordination is particularly important when establishing rain loads." 


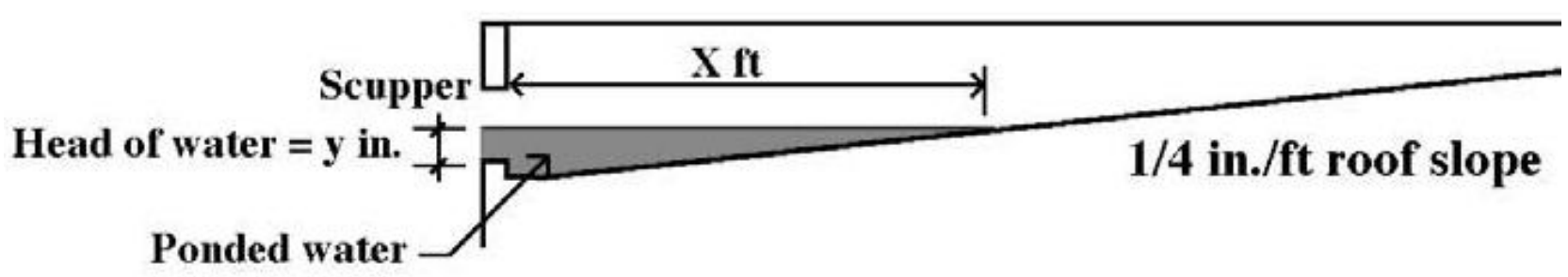

Figure 2 - Ponded water weight behind a properly operating drainage scupper (Source: Patterson 2010)

With the architect directing the flow to the drains or scuppers and the plumbing consultant sizing the drains and their route out of the building, it has been standard practice for the structural engineer to have a passive role in the drainage design, simply designing the roof structure for dead and live loads with a given roof slope set forth by the architect. Historically, an engineer's standard of practice has been to simply leave all the drainage issues to others, or at most check whether the specified roof slope is sufficient to prevent ponding instability (1/4-inch per foot under ASCE 7-10 Section 8.4). Figure 3 illustrates the responses from a 2013 online poll conducted during a roof drainage webinar by SE University, a continuing education provider for structural engineers. Less than $10 \%$ take an active role in the design of the roof drainage system. In general the belief is that special loading situations created on the roof, whether from roofing materials, mechanical, electrical, plumbing equipment, building facades, or even excessive rain loads, should be explicitly communicated to the engineer by the design professionals who are most familiar with and have control over the magnitude of those loads.

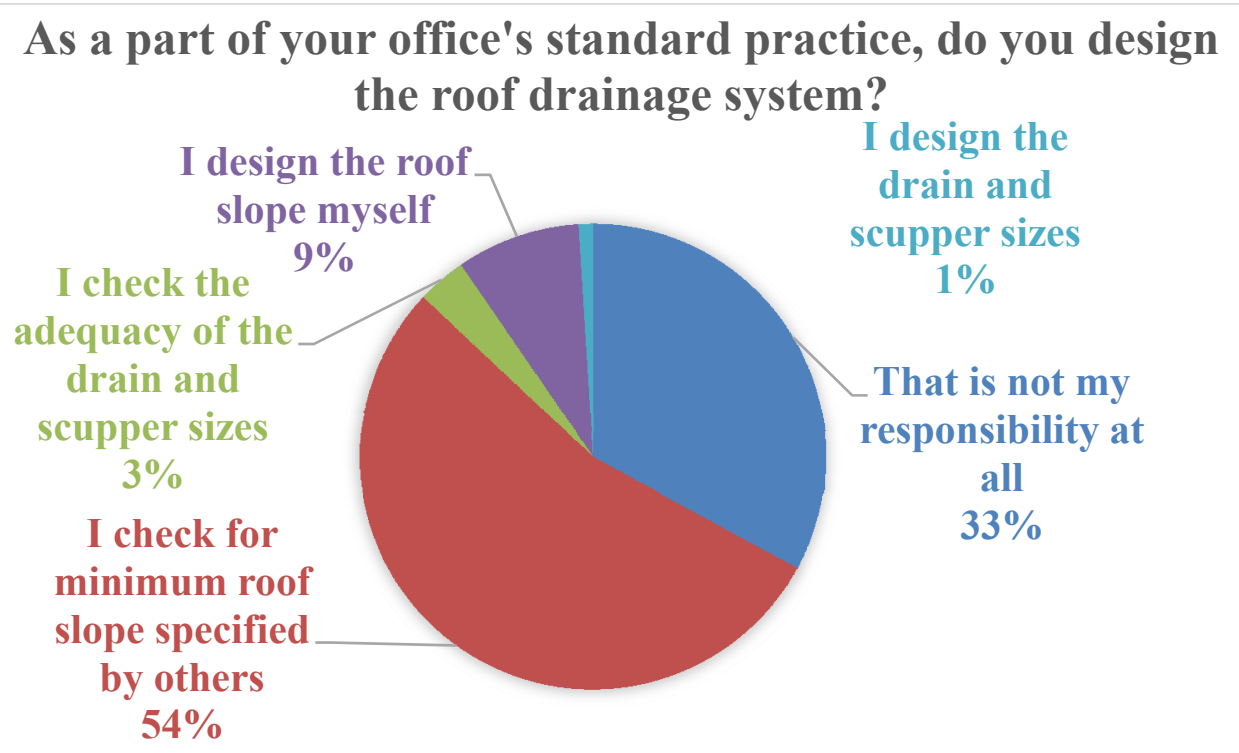

Figure 3 - Polling Survey Results. Based on 292 separate, anonymous polling responses during SE University Webinar "ASCE 7 Ponding and Roof Drainage: Not my problem ... maybe" September 11, 2013.

Various passages from the portions of the governing codes may imply responsibility for who is to address the rainwater loads. Depending upon the local jurisdiction having authority, in the United States there are two different plumbing codes commonly adopted: the Uniform Plumbing 
Code (UPC) (IAPMO 2012) and the International Plumbing Code (IPC) (ICC 2012b). UPC Section 1101.11.1 states that for the primary roof drainage "The location and sizing of drains and gutters shall be coordinated with the structural design and pitch of the roof," implying that the plumbing consultant has responsibility to consider how his design is affected by or limited by the structural engineer's design. Similarly, the UPC and the IPC state that scuppers acting as the secondary (emergency) roof drainage system "shall be sized to prevent the depth of ponding water from exceeding that for which the roof was designed...." implying that the responsibility to not overload the roof structure falls on the plumbing consultant who is designing the drainage system, assuming that the structural engineer's design load has been provided to him through some means. Furthermore for the design of the scuppers, UPC Table D4.1 Note 4 instructs the drainage designer to coordinate the allowable water head with the roof structural design, and in UPC Appendix D Section D4.1 it states "The maximum allowable level of water on the roof should be obtained from the structural engineer, based on the design of the roof". Clearly this language places the burden on the drainage system designer who must obtain the allowable rainwater loading information from the structural engineer, but how common is it for this communication to occur? An online poll conducted during an SE University webinar on roof drainage found that $60 \%$ of respondents had never been asked for rainwater weight limits during their careers and another $26 \%$ having only been asked once or twice (See Figure 4). For the purpose of the UPC, it appears more communication is needed between the design consultants.

\section{In your entire experience, how often has a plumbing consultant asked you, the engineer, for the maximum water weight allowed on the roof?}

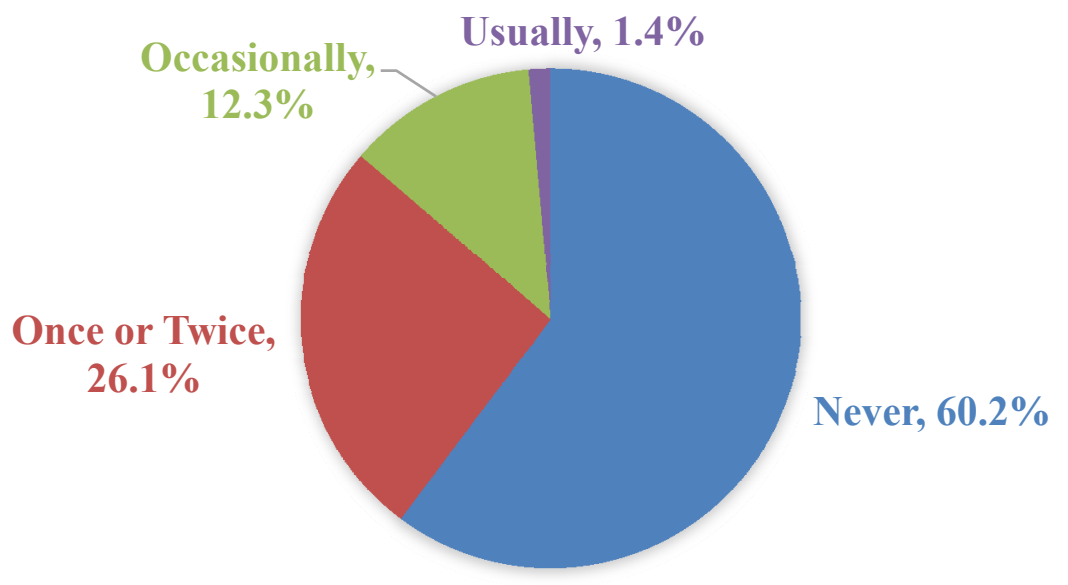

Figure 4 - Polling Survey Results. Based on 211 separate, anonymous polling responses during SE University Webinar “ASCE 7 Ponding and Roof Drainage: Not my problem ... maybe” September 11, 2013.

The IBC places a similar burden on the drainage designer to stay within the constraints of the roof structure design. For the design of scuppers as secondary (emergency) roof drainage, 2012 IBC Section 1503.4.2 states that "When scuppers are used for secondary (emergency overflow) roof drainage, the quantity, size, location and inlet elevation of the scuppers shall be sized to prevent the depth of ponding water from exceeding that for which the roof was designed...." 


\section{ROLE OF THE STRUCTURAL ENGINEER}

While much of the burden of protecting against rainwater overloads falls on those designing the drainage system, the structural engineer also must consider the rainwater loads. In 2012 IBC Section 1611.1 and ASCE 7-10 Section 8.5, the building's rain load $R$ specifically includes water weight that accumulates with some head height at the roof drainage collection points, in addition to investigating the potential for ponding instability on susceptible framing bays per ASCE 7-10 Section 8.4. Ponding instability begins as deflection under the water weight progresses causing more and more water to be retained on very flat and flexible roof structures.

\section{WATER ACCUMULATION AT DRAINAGE COLLECTION POINTS}

It is clear that the structural engineer must think about the weight of the rainwater that accumulates at the drainage points, as evident in the following 2012 IBC passage:

1611.1 Design rain loads. Each portion of the roof shall be designed to sustain the load of rainwater that will accumulate on it if the primary drainage system for that portion is blocked plus the uniform load caused by water that rises above the inlet of the secondary drainage system at its design flow. The design rainfall shall be based on the 100-year hourly rainfall rate indicated in Figure 1611.1 or on other rainfall rates determined from approved local weather data.

The structural engineer needs to be given the anticipated depth of rainwater or water weight accumulating at the roof drain. Often the structural engineer is working ahead of the plumbing consultant, and thus may not be in a position to obtain it. Alternatively, it may be beneficial to set a maximum limit for the plumbing consultant instead of waiting to check the final design.

To compute the rainwater roof load, rainfall intensity maps (2012 IBC Figure 1611.1) are consulted, developed by the National Weather Service for a 1-hour event with a 100-year return period storm. After determining the precipitation depth for a 1-hour design rainfall in inches, $P D_{1-h r / 100-y r}$, the required design flow rate in gallons per minute $(\mathrm{gpm}) q$ for a drain is illustrated in Equation (1) as simply the hourly precipitation depth multiplied by each drain's tributary collection area $A_{\text {Trib }}$ in square feet, with the proper unit conversions.

$q(\mathrm{gpm})=P D_{1 \mathrm{hr} / 100 \mathrm{yr}} \times A_{\text {Trib }} \times \frac{1 \mathrm{ft}}{12 \mathrm{in}} \times \frac{7.48 \mathrm{gal}}{\mathrm{ft} \mathrm{t}^{3}} \times \frac{1 \mathrm{hr}}{60 \mathrm{~min}}$

Equation (1)

\section{A ROOF COLLAPSE CASE-STUDY: WATER FLOW AND ACCUMULATION}

In December 2014, the roof structure of a large warehouse in Santa Maria, California partially collapsed during an intense rain storm (Figure 1). The low-sloped roof structure consisted of light gage steel decking supported by open-web steel joists and rolled wide-flange girders, supported by interior steel columns and a perimeter tilt-up concrete bearing wall system with parapets. The drainage collection system consisted of interior primary drains with dome strainer caps (which clogged by leaves) and secondary scuppers through the parapet. The IBC design rainfall intensity is estimated at $P D_{1-h r / 100-y r}=1.5$-inches per hour. With the primary drain clogged, the scupper was fed by 21,800 square feet of tributary roof area resulting in a design flow $q=340$ gallons per minute. As required by 2012 IBC Section 1611.1, the structural engineer must design the roof structure "to sustain the load of rainwater that will accumulate on 
it if the primary drainage system for that portion is blocked plus the uniform load caused by water that rises above the inlet of the secondary drainage system at its design flow."

Making matters worse, the secondary drainage system inlet is required to be set at a higher elevation than the primary drain (IBC Section 1611.3); and often the inlet is significantly higher than the roof surface causing water to rise before the secondary drainage provides any relief. When the secondary drainage is an interior conductor, 2012 UPC Section 1101.11.2.2 requires it to be two-inches above the roof surface, but also "shall be a height to prevent the depth of ponding water from exceeding that for which the roof was designed...." Architects often raise the scupper inlets two-inches or more above the roof, as it is considered undesirable to have emergency scuppers spilling water down and staining building sides in non-emergency situations. Raising the secondary drainage system inlet elevation above the roof surface directly contributes to additional ponding water loading at the low portions of the roof.

Continuing with our Santa Maria case study, the necessary scupper flow rate through a parapet wall is estimated using a channel type weir equation, where the water flow is bounded on three sides while open at the top. The weir flows in 2012 UPC Table 4.1 are based on the Francis Formula, presented here in Equation (2) in a format consistent with typical units in the United States, where the flow rate $q$ is provided in gallons per minute, using the width (breadth) of the opening in inches, $b$, and the head height of the water in inches, $h$.

$q=3.0(b-0.2 h) h^{3 / 2}$

Equation (2)

The required secondary scupper design flow $q=340 \mathrm{gpm}$ was previously estimated. The actual building parapets contained rough overflow scupper penetrations of $11 \frac{1}{2}$-inch wide by 8 -inch tall, and after flashing and roofing installation the net scupper size at the time of collapse was found at one location to be approximately 11 -inch wide by 6 -inch tall. It is important to evaluate what hydraulic head height is necessary to achieve the $340 \mathrm{gpm}$ flow, because the resulting water weight could be excessive. Using Equation (2), the necessary head height $h$ is 5.05 -inch. This head height is added to the inlet elevation above the roof to obtain the total water depth at the drain. As mentioned, the inlet elevation is often specified a minimum of 2-inches above the low point of the roof; however in this building, the actual inlet elevation was estimated to be approximately 3.5 -inches above the roof surface. Therefore the total rainwater depth at the drain is a total of $5.05+3.5=8.55$-inches or approximately 44 pounds per square foot (psf) of rain load. The concept of this total water weight accumulating near the drain is shown in Figure 2.

Rain load $R$ and roof live load $L_{r}$ are not combined together in the IBC load combinations; however, in this warehouse case study the rain load $R$ of 44 psf clearly exceeds a basic unreduced roof live load $L_{r}$ of $20 \mathrm{psf}$. In situations where the roof has sufficient slope, the effect of the high rainwater weight might be limited to only framing members in the vicinity of the drainage point as shown in Figure 2.

A designer may alternatively design a wider scupper to reduce the water head height $h$ such that the rain load $R$ on the roof is below the basic $20 \mathrm{psf}$ live load design. In order to achieve this, an approximate 4-inch water depth would be the maximum allowed. In the Santa Maria building where the inlet elevation was estimated at 3.5-inches high, only $1 / 2$-inch of hydraulic head height 
is available, making a scupper essentially nonfunctional at this water depth forcing a different approach. However, consider a situation in a new building where the scupper inlet at the common practice 2-inch minimum elevation above the roof surface, leaving 2 -inches of head height available for flow. Using Equation (2), the Francis Formula, the necessary scupper width $b$ to obtain the case study's 340 gpm design flow is determined to be $b=41$-inches.

A rectangular scupper 41-inches wide does not seem very desirable architecturally or structurally in the parapet. This illustrates that it might not always be realistic to expect the plumbing consultant to design the drainage system within the confines of the engineer's basic roof design live load. Alternatively, the plumbing consultant could place a tributary drainage area limitation on the building, but that might not be possible or desirable in all situations. In large buildings, that approach may lead to drains at the interior of the buildings far away from the exterior walls, preventing the use of more reliable scuppers.

For a more proactive approach, the design team may have the structural engineer simply add some additional strength to the gravity carrying system in the vicinity of all roof drains and scuppers to accommodate the larger rainwater weight. It seems reasonable for the engineer to set some upper rain load limits, then to design the roof framing in the drain vicinity for a selected maximum water depth, and communicate that maximum assumed depth to both the architect and plumbing consultant. For example, designing for a maximum water depth of 6-inches in the vicinity of the drainage low point, and limit the scupper inlet height to 2-inches above the roof low point, thus providing a net 4-inch head of water for flow. The 4-inch head achieves decent scupper flow rates as illustrated in UPC Table D4.1. In the Santa Maria warehouse case-study, the necessary scupper width $b$ in conjunction with a 4 -inch water head is 15 -inches (assuming a standard 2-inch inlet elevation). This is a more realistic scupper size than the 41-inch wide rectangular size for a 2 -inch maximum head previously theorized. The 6-inch water depth limit results in a maximum 31.2 psf of rain load in the vicinity of the drain that must be designed for.

Most often these low-sloped roof systems consist of either untopped metal decking or wood roof framing; and because these roofs are especially lightweight, excessive ponding water weight can quickly overwhelm their gravity design capacity. But even with a blocked primary drain, the accumulated water weight in the vicinity of a functioning secondary drain or scupper only modestly overloads the roof in a localized region. A roof collapse from accumulating water weight at a fully functioning drain during a design rainfall intensity is not very likely even when the structural design did not consider the possibility of accumulating rainwater on a sloped roof. Instead, insufficient drainage design or drainage operation are the typical causes. Never the less, it is wise for the structural engineer to consider the accumulating rain load in his design to avoid the appearance by a layperson that he contributed to the collapse in some small way.

\section{INVESTIGATING PONDING INSTABILITY}

In low-sloped roof systems, decking, beams or joists may have some initial sag or deflection allowing water to pool or collect, adding load, causing more deflection, and thus collecting more water load, and thus more deflection, and so forth. This progressive deflection and loading sequence of events may lead to a ponding instability failure where the water weight eventually overwhelms the roof structure strength. Sufficient roof slope and/or roof stiffness is necessary to prevent ponding instability. Although uncommon, at times roof systems are installed dead flat, 
and then water pools to some depth or hydraulic head before it can sufficiently flow through the drainage system. These dead-flat conditions are very susceptible to ponding instability, and must have significant strength and stiffness to preclude collapse failure.

With this in mind, the IBC requires a ponding investigation for framing bays designated as being susceptible to ponding instability. Framing bays where roof slopes are less than $1 / 4$ " per foot are considered susceptible and "shall be investigated by structural analysis to assure that they possess adequate stiffness to preclude progressive deflection (i.e. instability) as rain falls on them..." (ASCE 7-10 Section 8.4). Historically, the 1/4-inch per foot roof slope magnitude has been considered to be sufficiently steep to overcome long-term dead load deflections and construction tolerances which potentially result in flat portions susceptible to ponding (ASCE 705 Section C8.4). Additional work investigating the theoretical member stiffness needed to eliminate flat roof portions for given roof slope magnitudes was conducted by Lawson (2012).

ASCE 7-10 introduced new language in Section 8.4 defining another susceptible bay condition. Regardless of whether the roof is sloped more than $1 / 4$-inch per foot or not, water that collects and backs-up at a blocked primary drainage point, despite having fully functional secondary drainage, is deemed as a susceptible bay prompting a ponding instability investigation.

On steel roof systems, a suitable analysis to determine if a roof has sufficient strength and stiffness is found in the Specification for Structural Steel Buildings (AISC 2010). In its Appendix 2 , a conservative procedure is provided to ensure two-way structural systems are sufficiently stiff to avoid ponding instability failure. A two-way system is an assembly of primary members (decking, joists, beams) and secondary members (beams, girders) in which both primary and secondary members are sufficiently flexible to have significant contribution to the overall ponding instability.

On wood roof systems, the current National Design Specification for Wood Construction (AWC 2012) does not have specific provisions for determining the adequacy of the roof's structural stiffness. However a predecessor, Standard for Load and Resistance Factor Design for Engineered Wood Construction (AF\&PA 1996) does provide a methodology to checking adequacy of two-way systems in its Appendix A3.

In wood roof systems where either the primary or secondary members are relatively stiff compared with the other, a simplified one-way approach is useful as described in the Timber Construction Manual (AITC 2005). This basic approach simply ensures that 1-inch of water weight does not lead to more than $1 / 2$-inch of deflection, and the resulting design stresses are checked with a magnification factor provided in the text. Also the magnification factor addresses the effects of long-term creep and variation in modulus of elasticity for wood materials. Additional work investigating the theoretical member stiffness needed to eliminate flat roof portions for given roof slope magnitudes considering long-term creep, variation in modulus of elasticity and load duration was conducted by Lawson (2012).

\section{A ROOF COLLAPSE CASE-STUDY: PONDING INSTABILITY}

Returning to the Santa Maria building that suffered a partial roof collapse discussed earlier with regards to scupper sizing, the structural design may have played a role in terms of ponding 
instability. More specifically, the main girder system was comprised of rolled wide flange beams in a double cantilever framing system (Figure 5). These efficient systems use fine-tune the cantilever lengths to theoretically balance positive and negative flexural demands under uniform gravity loads, resulting in smaller section sizes. This type of system does however require special attention evaluating lateral torsional buckling instability at the negative moment region that extends from points of inflection to the cantilever end. In the Santa Maria building, constructed in the late 1960's, no such lateral stability bracing existed.

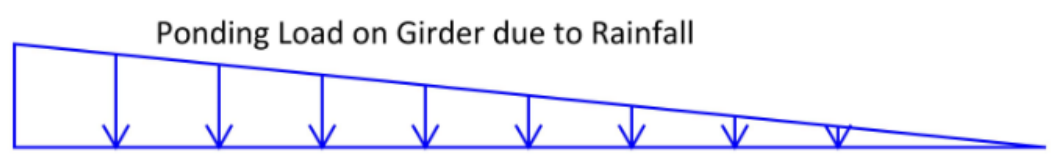

Typical Uniform Gravity Load
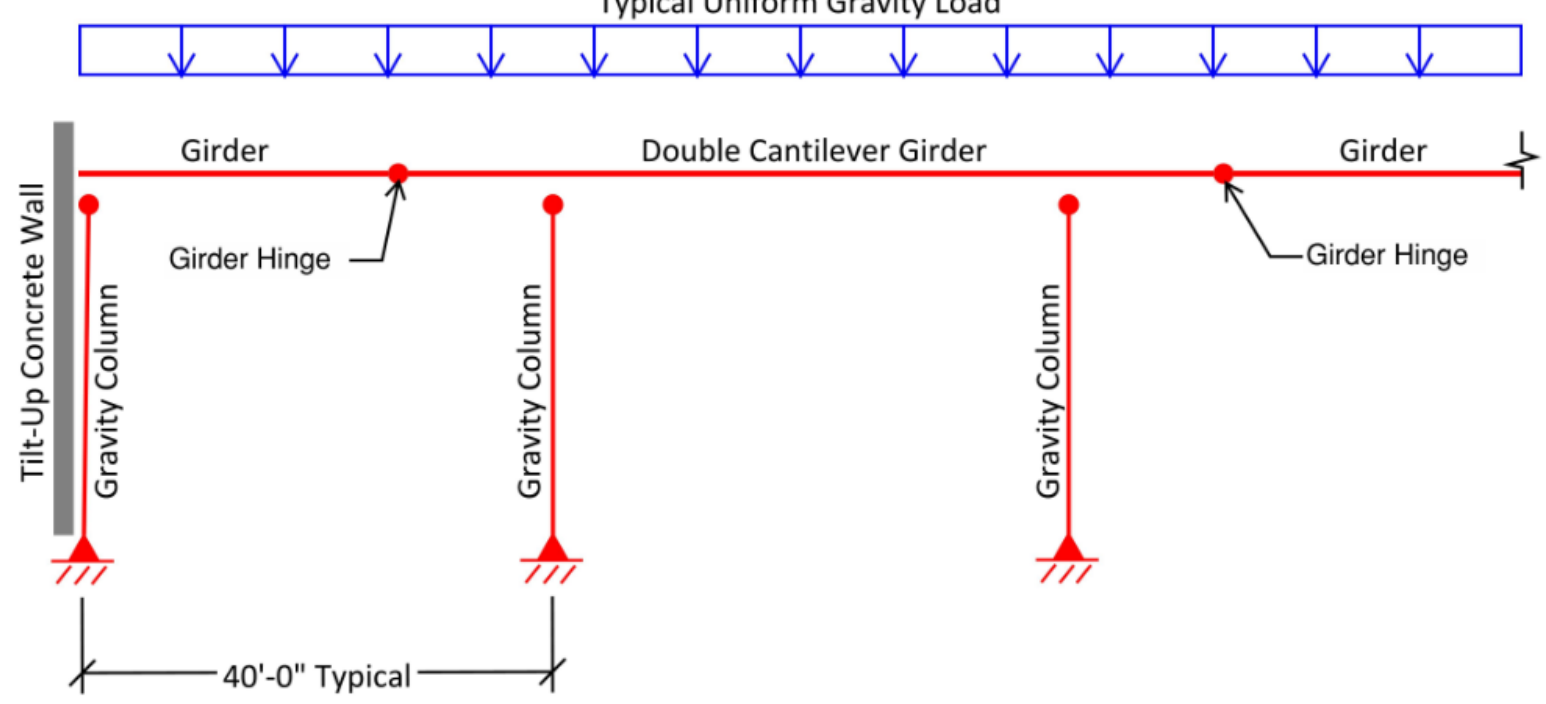

Figure 5 - Framing Configuration for Santa Maria Warehouse.

When water ponded on the roof during the rain event in December 2014, it loaded the perimeter beams first, and slowly created an increasingly unbalanced loading condition on the main girders. Without direct lateral bracing for stability, this unbalanced loading eventually exceeded the minimal bracing capacity of the girder-column connection. The horizontal movement of the girder bottom flange caused by lateral torsional buckling created a sudden P-delta instability at the top of the gravity column, leading to the collapse (See Figure 6).

\section{RAINFALL INTENSITY}

The design of the roof drainage system is all under the backdrop of the assumed rainfall intensity. Currently the UPC, IPC, IBC, and ASCE 7 all provided guidance using a 1-hour rainfall intensity for a 100-year storm. For the Santa Maria Building example, maps in 2012 IBC indicate this intensity as approximately 1.5 -inches for design. Actual rainfall records obtained from a site approximately 1-mile to the south indicate the storm that led to the collapse dropped approximately 1.44-inches in the worst 1-hour duration time frame. However, when evaluated over shorter durations, the hourly rate of rainfall was more intense, easily exceeding 2-inches. 


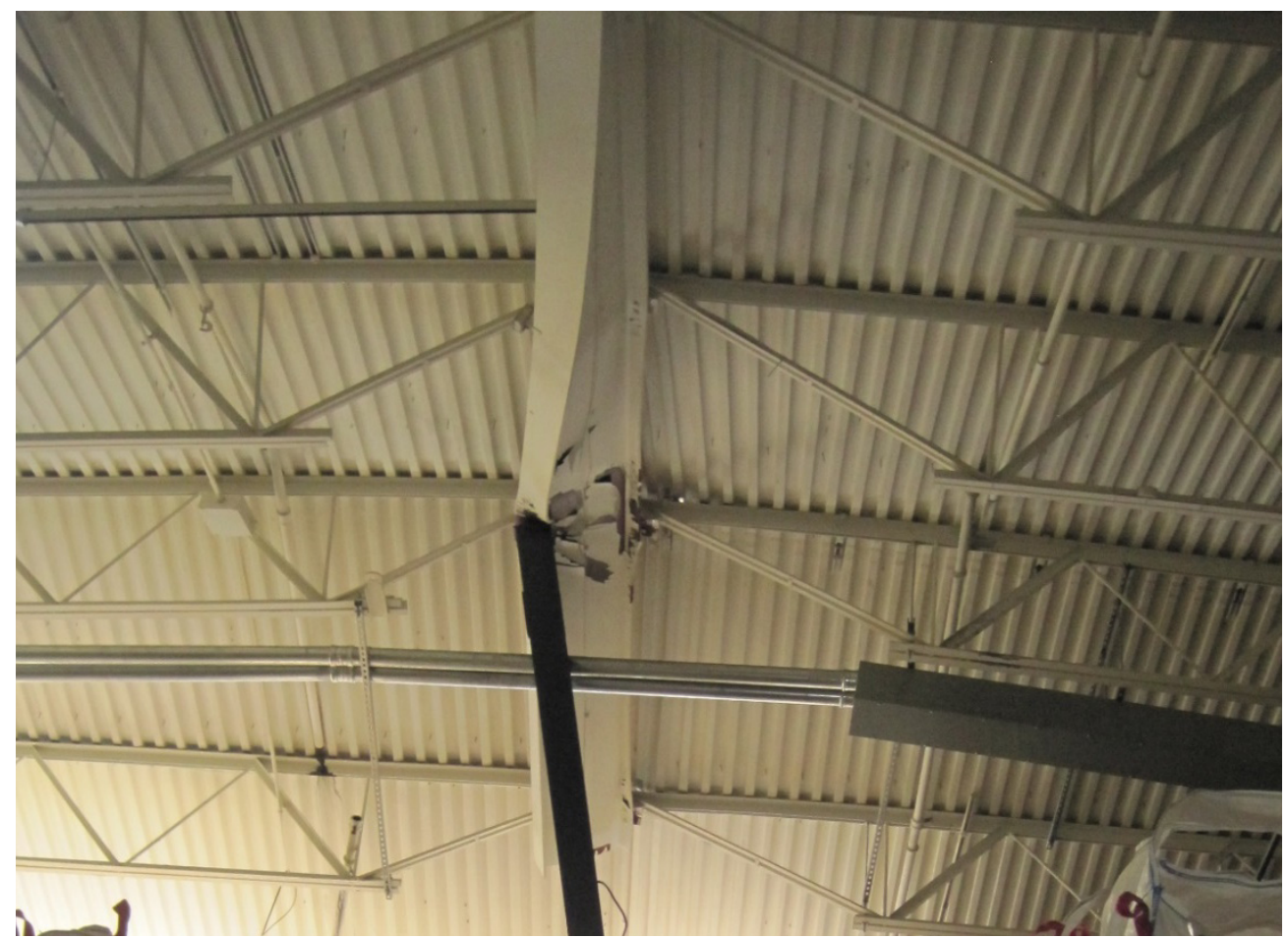

Figure 6 - Girder to Column Stability Failure (Source: Michael Parolini)

While this case study building may have experienced a 1-hour rainfall intensity slightly less than the IBC requirement, it is important to think about the appropriateness of the 1-hour duration for a roof. As storm intensities go, shorter duration times have a greater likelihood of stronger rainfall intensities. Considering it takes far less than an hour's time for rainwater to travel and collect at a roof drain, it has been argued that roof drainage systems should be designed for intensities significantly less than the current 1-hour design standard (Dregger 2012).

\section{CLOSING REMARKS}

The collapse of lightweight low-sloped roof structures occurs too often during rain storms. While the culprits most often appear to be an inadequately sized or clogged drainage system, all the design parties can be pulled into the litigation simply to find more money to settle the damage claim. In states with a joint-and-several liability system such as California, jurors or arbitrators only need to believe that the standard of care was not met and that contributed in some amount (even a small amount) to the damages. Even if everyone agrees the primary cause of the roof collapse was a drain system clogged with leaves resulting in 18-inches of water on the roof, a drain undersized by only $10 \%$ or a roof beam overstressed by $10 \%$ under the required design conditions could bring the architect or structural engineer into the litigation.

To avoid landing into this kind of trouble, whether justified or not, the architect, structural engineer, and plumbing consultant of low-sloped roof systems should all coordinate with each other how the rainwater is to be transported off the roof, paying particular attention to slopes less than $1 / 4$-inch per foot and areas where rainwater collects awaiting discharge down a drain pipe or out a scupper. Additionally, the owner and/or tenant of a building should be impressed upon to maintain a debris-free roof surface and clog-free domed strainer drain caps. 


\section{REFERENCES}

AF\&PA (American Forest \& Paper Association). (1996). Standard for Load and Resistance Factor Design for Engineered Wood Construction, AF\&PA/ASCE 16-95, ASCE, New York.

AISC (American Institute of Steel Construction). (2010). Specification for Structural Steel Buildings, (AISC 360-010), AISC, Chicago, Illinois.

AITC (American Institute of Timber Construction). (2005). Timber Construction Manual, Fifth edition, AITC, John Wiley \& Sons, Hoboken, New Jersey.

ASCE (American Society of Civil Engineers). (2005). Minimum Design Loads for Buildings and Other Structures, Standard ASCE 7-05, ASCE, Reston, Virginia.

ASCE (American Society of Civil Engineers). (2010). Minimum Design Loads for Buildings and Other Structures, Standard ASCE/SEI 7-10, ASCE, Reston, Virginia.

AWC (American Wood Council). (2012). National Design Specification for Wood Construction (2012 NDS), AWC, Leesburg, Virginia.

Dregger, P. (2012). "Roof Collapse, Part I - A Roofing Contractor's Nightmare." Western Roofing Magazine, Vol. 35, No. 6, November/December 2012, Dodson Publications, Reno, Nevada.

IAPMO (International Association of Plumbing and Mechanical Officials). (2012). Uniform Plumbing Code, 2012 edition, IAPMO, Ontario, California.

ICC (International Code Council). (2012a). International Building Code, 2012 edition, ICC, Washington DC.

ICC (International Code Council). (2012b). International Plumbing Code, 2012 edition, ICC, Washington DC.

Jordan, J. W. (2005). "Roof Drainage Design and Analysis: Structural Collapses, Responsibility Matrix, and Recommendations." Proceedings of the 2005 Structures Congress and 2005 Forensic Engineering Symposium, American Society of Civil Engineers, Reston, Virginia.

Lawson, J. W. (2012). "Roof Drainage: Not my problem...Maybe." SEAOC 2012 Convention Proceedings, Structural Engineers Association of California, Santa Fe, New Mexico.

Patterson, S. L., and Mehta, M. (2010). "Life Safety Issues in Roof Design." Proceedings of the RCI $25^{\text {th }}$ International Convention, RCI, Inc., Raleigh, North Carolina, pp. 191-212.

Verhulst, S. M., Deleon, M. A., and East B. L. (2010). "The Roof Drainage Epidemic.” Forensic Engineering 2009: Pathology of the Built Environment, Proceedings of the Fifth Congress on Forensic Engineering, American Society of Civil Engineers, Reston, Virginia, pp. 204 to 214. 